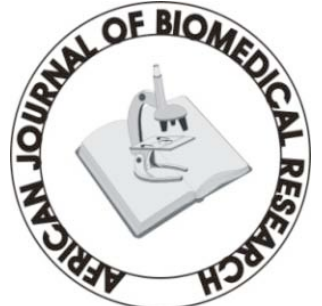

Full-text available at http://www.ajbrui.com http://www.bioline.br/md http://www.ajol.com

Received:

February 2008

Accepted (Revised):

June 2008

Published

Septemebr 2008
Full Length Research Article

\section{Maternal Mortality in a Nigerian Maternity Hospital}

\author{
*Olopade, F.E. and Lawoyin, T.O. \\ Department of Community Health, College of Medicine, \\ University of Ibadan, Nigeria.
}

Despite recent focus on maternal mortality in Nigeria, its rates remain unacceptably high in Nigeria. A retrospective case-control study was carried out at Adeoyo Maternity Hospital, Ibadan between January 2003 and December 2004. This was to determine the maternal mortality ratio in a secondary health facility, to identify the causes of death and to assess factors associated with these deaths. The case files of all maternal deaths that occurred in the hospital during the two years period were retrieved and data extracted into a study proforma. Each maternal death was matched with three controls that delivered the same day and live around the same area of Ibadan. Bivariate analysis of the data was done with the cases and controls compared in relation to various risk factors. There were 8,724 lives births and 84 maternal deaths giving a MMR of $963 / 100,000$ live births. The main causes of the death were haemorrhage $20(23.8 \%)$ sepsis $20(23.8 \%)$ and eclampsia 14(16.7\%). Nine women (10.7\%) died while pregnant, $11(13.1 \%)$ died in labour, $52(61.7 \%)$ died after delivery while $12(14.3 \%)$ died from post-abortal complications. Most of the deaths due to post-partum heamorrhage $(66.7 \%)$ were seen in mothers over the age of 29 years while $64.2 \%$ of deaths due to eclampsia were in women under the age of 25 years due to eclampsia occurred in nulliparous women and PPH was responsible for deaths in more women as their parity increased from two. From bivariate analysis, factors significantly associated with maternal death included unbooked status \{Odd's ratio OR=12.89 (95\%C.I. _ 6.9 24.1) $\mathrm{p}<0.05\}$, grandmultiparity (parity $>5)\{\mathrm{OR}=4.17(95 \%$ C.I. $-1.53-11.45) \mathrm{p}<0.05\}$ and prolonged labour $(>18$ hours) $\{\mathrm{OR}=2.86$, (95\% C.I. $1.5-5.9) \mathrm{p}<0.05\}$. It is necessary to improve the quality of emergency obstetric service as well as reduce the cost and to educate women of reproductive age in Ibadan on the importance of booking for antenatal care and family planning.

(Afr. J. Biomed. Res. 11: 267 - 273)

Key words: Maternal mortality, case-control study, maternal death, antenatal care, emergency obstetric care

*Corresponding author's address: funmiolopade@yahoo.com

Abstracted by:

African Index Medicus (WHO), CAB Abstracts, Index Copernicus, Global Health Abstracts, Asian Science Index, Index

Veterinarius, Bioline International, African Journals online 


\section{INTRODUCTION}

Pregnancy and childbirth is a normal physiological process bringing a joyful experience to individuals and families. However, in many parts of the world, pregnancy and childbirth is a perilous journey, a risky and potentially fatal experience for millions of women especially in developing countries. This is in spite of evidence which shows that motherhood can be safer for all women (De Browere, 1998), by a set of life-saving strategies that can work even in low resource settings (Shiffman, 2000).

The average maternal mortality rates in developed countries is between 10-15/100,000 live births while developing countries record rates 100200 times this number (Rosenfied, 1989). The problem of maternal deaths is worst in sub-Saharan Africa with the maternal mortality rates there being higher than anywhere else in the world (WHO, 2004). The situation in Nigeria is especially grave as we still record maternal mortality rates in the order of $800-1,000$ per 100,000 live births (N.P.C. 2003) and thus rank among the nations with the highest number of maternal deaths (WHO, 2004). Nigeria makes up only $1.7 \%$ of the total world population, but accounts for about $10 \%$ of the global estimate for maternal mortality (Grant, 1990).

A lot of work has been done on maternal mortality in tertiary health institutions, which have a high selection of complicated cases. In order to obtain a true picture of the epidemiology of maternal mortality in Ibadan, this study was carried out in a secondary health facility to which primary health care facilities refer patients.

\section{MATERIALS AND METHODS}

This is a retrospective case - control study of maternal deaths which was conducted in Adeoyo Maternity Hospital. It is an 80-year-old state-owned General Hospital in Ibadan city, Nigeria. It is highly patronized by Ibadan residents especially those of low and middle socio-economic status. It also serves as a referral center for many primary health centers and private clinics within Ibadan and its environs.

The Obstetrics and Gynaecology department of the hospital has 2 consultants and about 10 doctors including medical officers, senior medical and principal medical officers. There is no blood bank in the hospital and patients are required to procure blood from the State Transfusion Service or private laboratories around the hospital. The 16 bedded labour ward records a delivery rate of 4,000-45,000 annually.

All the maternal deaths that took place at the hospital between January 1, 2003 and December 31, 2004 (a 2-year period) were identified. A maternal death was defined as the death of a woman while pregnant or within six weeks of the end of pregnancy irrespective of the duration or site of the pregnancy, from any cause related to or aggravated by pregnancy and its management (WHO, 1992). Each maternal death was matched with three controls that delivered on the same day and live within the same ward and similar socio-economic area of Ibadan. The case files of all these women were retrieved from the Medical Records Department and data extracted into a study proforma focusing on socio-demographic and obstetric characteristics including age, parity, occupational status, booking status, season of delivery and length of hospital stay before death as well as cause of death where applicable. Data were entered into a computer database using SPSS version 12 and statistical analysis was performed. Bivariate analysis was done using Epi-info 6. The odd's ratios were generated to establish the exposure as a risk factor for death. Maternal mortality ratio was calculated as the number of maternal deaths per 100,000 live births (WHO, 1992).

Ethical approval was obtained from the Oyo State Ethical Review Committee and the management of the facility used.

\section{RESULTS}

During the study period, a total of 84 maternal deaths and 8,724 live births were recorded at the hospital. Table 1 shows a review of the sociodemographic characteristics of the cases and controls and reveals no significant differences between them except for parity and booking status. Most of the women $(70.2 \%$ of the cases and $72 \%$ of the controls) were unskilled, mainly petty traders.

The study maternal mortality ratio was 
calculated as 963/100,000 live births. Direct obstetric deaths were $75(89.3 \%)$ while indirect obstetric deaths were $9(10.7 \%)$. About $61.9 \%$ of the maternal deaths occurred post-partum, $13.1 \%$ intrapartum and $10.7 \%$ ante-partum while $14.3 \%$ of the women died from post-abortal complications. The main causes of death were haemorrhage $20(23.8 \%)$, sepsis $20(23.8 \%)$, eclampsia $14(16.7 \%)$, postabortal complications $11(13.1 \%)$ and obstructed labour 10 (11.9\%) (Figure 1).

Table 1: Socio-Demographic Pattern of Cases

\begin{tabular}{ll}
\hline Characteristics & Cases $\mathbf{N}(\%)$ \\
\hline AGE (YEARS) & $6(7.1)$ \\
\hline $15-19$ & $15(17.9)$ \\
\hline $20-24$ & $35(41.7)$ \\
\hline $25-29$ & $20(23.8)$ \\
\hline $30-34$ & $8(9.5)$ \\
\hline$\geq 35$ & \\
\hline PARITY & $21(25)$ \\
\hline 1 & $12(14.3)$ \\
\hline 2 & $17(20.2)$ \\
\hline 3 & $11(13.1)$ \\
\hline 4 & $10(11.9)$ \\
\hline$\geq 5$ & $11(13.9)$ \\
\hline Not recorded & $2(2.4)$ \\
\hline OCC. STATUS & $6(7.2)$ \\
\hline Higher (Prof. and Skilled & $59(70.2)$ \\
\hline Lower (Unskilled) & $19(22.6)$ \\
\hline Unemployed & $23(27.4)$ \\
\hline BOOKING STATUS & $61(72.6)$ \\
\hline Booked & $36(42.9)$ \\
\hline Unbooked & $48(57.1)$ \\
\hline SEASON OF DELIVERY & \\
\hline Dry (November-March) & \\
\hline Wet (April-October) & \\
\hline
\end{tabular}

Table 2 compares the obstetric history of the cases with their various causes of death.

Age and Cause of Death: Most of the deaths due to post-partum haemorrhage $(66.7 \%)$ occurred in women over 29 years of age while $64.2 \%$ of the deaths due to eclampia were in women under 25 years of age.

Parity and Cause of Death: Of the deaths due to eclampia, $71.4 \%$ occurred in nulliparous women while post-partum haemorrhge as a cause of death increased significantly as the parity of the women increased; no deaths in women with parity below $2,23.5 \%$ of deaths in women with parity of 2 , and $36.4 \%$ of women with parity $\geq 5$.

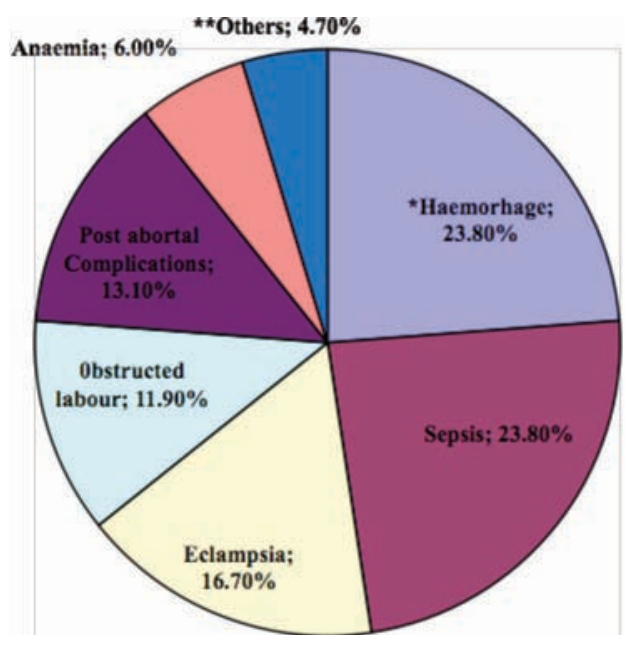

Figure 1: Causes of Maternal Death at Adeoyo Maternity Hospital (2003-2004)

*Includes ante-partum haemorrhage (APH) and post-partum haemorrhage $(P P H) * *$ Anaesthetic deaths, Pulmonary TB.

Length of admission and Cause of Death: Most of the eclamptic deaths (85\%), deaths due to obstructed labour (80\%) and post-partum haemorrhage $(73.3 \%)$ occurred within 24 hours of admission, but at least $40 \%$ of deaths due to sepsis occurred after 72 hours of admission.

Booking Status and Cause of Death: Deaths due to sepsis $(75 \%)$, eclampsia (71.4\%), ante-partum haemorrhage (100\%) and obstructed labour $(80 \%)$ occurred more in unbooked women while almost equal proportions of booked and unbooked women died due to post-partum haemorrhage and anaemia.

Season of Delivery and Cause of Death: Significantly more eclamptic deaths were seen in the rainy season $\left(x^{2}=5.141\right.$ d.f. $\left.p=0.023\right)$ as well as deaths due to obstructed labour $\left(x^{2}=3.21\right.$ d.f. $\mathrm{p}=0.074)$ and post abortal complications $\left(\mathrm{x}^{2}=6.6\right.$ 1 d.f. $\mathrm{p}=0.01)$. All deaths due to anaemia occurred during the rainy season. From bivariate analysis, the risk factors identified to be associated with maternal death (See Table 3) were grandmultiparity (parity $\geq 5$ ), prolonged labour $(\geq$ 
18hours), raised blood pressure on admission ( $\geq$ $160 / 90 \mathrm{mmHg}$ ), lower occupational status and lack of antenatal care. The age of the mothers was not a significant risk factor for maternal death in this study. Teenage mothers (age <20yrs) and older mothers $(\geq 35 y r s)$ were not at a statistically significant risk of death.

\section{DISCUSSION}

The study maternal mortality ratio (MMR) of $963 / 100,000$ live births is higher than the national figure for Nigeria, which is 800/100,000 live births. However, it is lower than what is obtained in studies done in teaching hospitals around the nation which put the figure between 1,000 and 3,0000/100,000 live births (Oladapo et al., 2006; Daramola et al., 2004). This is believed to be a truer picture of the MMR in Ibadan since the study was carried out in a secondary health facility which does not have such a high selection of complicated cases as in the teaching hospitals and receives referred cases from the grassroots through the primary health care system.

Table 2: Obstetric History and Causes of Death

\begin{tabular}{|c|c|c|c|c|c|c|c|c|}
\hline Characteristics & $P P H$ & $A P H$ & Eclampsia & Sepsis & $\begin{array}{l}\text { Obst. } \\
\text { Labour }\end{array}$ & $\begin{array}{l}\text { Post abortal } \\
\text { Comp. }\end{array}$ & Anaemia & Others \\
\hline AGE (Yrs) & & & & & & & & \\
\hline $15-19$ & 0 & 0 & 4 & 1 & 0 & 1 & 0 & 0 \\
\hline $20-24$ & 1 & 0 & 5 & 3 & 1 & 2 & 1 & 2 \\
\hline $25-29$ & 4 & 5 & 1 & 12 & 4 & 4 & 4 & 1 \\
\hline $30-34$ & 8 & 0 & 2 & 3 & 4 & 2 & 0 & 1 \\
\hline$\geq 35$ & 2 & 0 & 2 & 1 & 1 & 2 & 0 & 0 \\
\hline TOTAL & 15 & 5 & 14 & 20 & 10 & 11 & 5 & 4 \\
\hline PARITY & & & & & & & & \\
\hline Nulliparous & 0 & 1 & 10 & 5 & 1 & 1 & 2 & 1 \\
\hline 1 & 0 & 0 & 0 & 4 & 4 & 2 & 1 & 1 \\
\hline 3 & 4 & 1 & 3 & 1 & 1 & 3 & 2 & 2 \\
\hline $3 \& 4$ & 7 & 2 & 1 & 7 & 2 & 4 & 0 & 0 \\
\hline 5 & 4 & 1 & 0 & 3 & 2 & 1 & 0 & 0 \\
\hline TOTAL & 15 & 5 & 14 & 20 & 10 & 11 & 5 & 4 \\
\hline $\begin{array}{l}\text { LENGTH OF } \\
\text { ADMISSION (Hrs) }\end{array}$ & & & & & & & & \\
\hline $0-24$ & 11 & 3 & 12 & 7 & 8 & 7 & 0 & 2 \\
\hline $25-48$ & 2 & 0 & 1 & 2 & 2 & 1 & 2 & 0 \\
\hline $49-72$ & 1 & 1 & 0 & 3 & 0 & 2 & 1 & 0 \\
\hline 72 & 1 & 1 & 1 & 8 & 0 & 1 & 2 & 2 \\
\hline TOTAL & 15 & 5 & 14 & 20 & 10 & 11 & 5 & 4 \\
\hline BOOKING STATUS & & & & & & & & \\
\hline Booked & 7 & 0 & 4 & 5 & 2 & 0 & 3 & 2 \\
\hline Unbooked & 8 & 5 & 10 & 15 & 8 & 11 & 2 & 2 \\
\hline TOTAL & 15 & 5 & 14 & 20 & 10 & 11 & 5 & 4 \\
\hline $\begin{array}{l}\text { SEASON OF } \\
\text { DELIVERY }\end{array}$ & & & & & & & & \\
\hline Dry (Nov.-Mar.) & 9 & 2 & 4 & 9 & 3 & 3 & 0 & 1 \\
\hline Wet (Apr.-Oct.) & 6 & 3 & 10 & 11 & 7 & 8 & 5 & 3 \\
\hline TOTAL & 15 & 5 & 14 & 20 & 10 & 11 & 5 & 4 \\
\hline
\end{tabular}


Table 3:

Risk factors Associated with Maternal Death

\begin{tabular}{|l|l|l|l|l|}
\hline Risk Factor* & Odd's Ratio & 95\% C.I. (Min.) & 95\% C.I. (Max.) & p- value \\
\hline Age < 20Yrs (20-34 Yrs) & 1.06 & 0.36 & 3.02 & 0.9 \\
\hline Age > 34 Yrs (20-34 Yrs) & 1.79 & 0.66 & 4.77 & 0.31 \\
\hline Nulliparity (Parity 1-4) & 0.75 & 0.04 & 1.37 & 0.31 \\
\hline Grandmultiparity (Parity 1-4) & 4.17 & 1.53 & 11.45 & 0.0026 \\
\hline Long labour (<18 Hours) & 2.86 & 1.39 & 5.9 & 0.0016 \\
\hline Raised Systolic B.P. (<160mmHg) & 5.44 & 2.15 & 13.96 & 0.000023 \\
\hline Raised Diastolic B.P. (<90 mmHg) & 2.64 & 1.41 & 4.93 & 0.00079 \\
\hline Dry season (Wet season) & 1.33 & 0.77 & 2.27 & 0.269 \\
\hline Higher occupational status (Lower Occ. Status) & 0.34 & 0.12 & 0.87 & 0.01 \\
\hline No antenatal care (At least one ANC visit) & 12.89 & 6.94 & 24.1 & 0.000001 \\
\hline 3-5 yrs birth interval (> 6yrs interval) & 0.3 & 0.08 & 1.14 & 0.073 \\
\hline
\end{tabular}

* Reference category in parenthesis

Obstetric haemorrhage and sepsis together accounted for almost half $(47.6 \%)$ of all maternal deaths in the study period. This reflects an inadequacy of the emergency obstetric response which is common to other developing countries (Matthews, 2005). Although haemorrhage may be an important cause of death in some developed countries, most of the deaths are due to ruptured ectopic pregnancy (Jacobs et. al., 1998) and not post partum haemorrhage (PPH) as we have here. PPH was found to be responsible for more deaths in older ( $\geq 30$ years), grandmultiparous (parity $\geq$ 5) women, which may be due to an increased incidence of uterine atony with increasing age and parity. About $70 \%$ of these deaths occurred within 24 hours of admission thus revealing that nothing short of rapid medical response including immediate arrest of haemorrhage and blood transfusion would save a woman with this condition. The absence of a blood bank within the hospital premises may have contributed to some of these deaths.

Sepsis, as a cause of death was not modified by age or parity of the mothers, though further statistical analysis needs to be done to ascertain this. However, it was noted that most of these deaths occurred after 48 hours of admission, thus indicating a longer course and a window of opportunity for intervention which was hardly utilized. Puerperal sepsis which is commonly complicated by anaemia can be adequately managed by aggressive antibiotic administration and blood transfusion when necessary. Patient who are unable to afford these are usually those that die.

Eclampsia is reported to be the most difficult of the obstetric emergencies to prevent and manage as well as the least understood (Howson et. al., 1995). Although it is not a common cause of death in industrialized countries, it is very common in developing countries (Duley 1992; Moodley and Daya, 1993). In this study, eclampsia occurred mostly in primigravidae $(71.4 \%)$ and young mothers $(<25$ years) $(64.3 \%)$ and over $70 \%$ of the deaths occurred in unbooked women. This is similar to findings by Onuh and Aisien (2004) who reported that eclampsia is most frequently seen in the first pregnancy and closely linked to lack of antenatal care. Antenatal care is indispensable to maternal health as it is needed for early detection and management of hypertension in pregnancy. Sadly, it is reported that only $63 \%$ of women in Africa receive antenatal care and fewer still deliver in a health care facility (WHO, 1997). This study also reports that $85.7 \%$ of the eclamptic deaths occurred within 24 hours of hospital admission, thus suggesting either late reporting by the patients or inadequate supportive therapy at the hospital.

Deaths due to obstructed labour occurred mainly in women aged between $25-34$ years (80\%) and in women that have delivered at least a child before. This may be due to delay on the part of the patients and their relatives as they may not readily consent to operative delivery since she had delivered vaginally in the past. Also, obstructed 
labour in multigravidae is more likely to lead to a ruptured uterus which has a high case fatality rate (Rush, 2000; Ahmed et al., 2004).

Over $90 \%$ of the maternal deaths due to post abortal complications were in women aged over $20 \mathrm{yrs}$ and those who had at least one child. This is interesting to note and is in agreement with the WHO (1998) conclusion that most women seeking abortion are married or live in stable unions and already have children; they seek abortion primarily to limit the size of their family or to space births. Most deaths from post abortal sepsis in an Indian study were also found to be in married women (Chhabra et. al., 2005). This is alarming because it points out the extreme importance of family planning which is not fully accepted in this environment. It is reported that less than $10 \%$ of Nigerian women in the reproductive age group are on modern contraception. There is the common belief that only promiscuous women use contraception, so most husbands do not allow their wives to use them. A massive campaign on family planning targeting the men and trying to change this mentality is needed to stop this ugly trend and save the lives of women.

Grandmultiparous women (parity $\geq 5$ ) had at least a four-fold increased risk of death when compared with those with parity $<5$. This is supported by various studies around the world (Garenne et al., 1997; Begum et al., 2003). These women need not have died if they had limited their family to less than five. Mothers who were unbooked for antenatal care also had a higher risk of death. This may be because they only present at the hospital when they have severe, sometimes life threatening complications (Harrison, 1997). Similarly, women who had prolonged labour $(\geq$ 18hours) faced a 3-fold increased risk of maternal death. Indeed they are more exposed to infection, maternal exhaustion and chances of instrumental delivery all of which increase their risk of death.

A raised blood pressure on admission $(\geq$ $160 / 90 \mathrm{mmHg}$ ) is usually an ominous sign as such women were 2-5 times more likely to die than those with normal blood pressure. It is important that such women are adequately cared for in order to prevent them from having convulsions and putting their lives and that of their babies at risk.
In general, women who had a lower occupational status were more likely to die than those with a higher status. This could be because the poorer ones are not able to afford the necessary management for their particular condition.

In conclusion, emergency obstetric care needs to be provided free or at a

highly subsidized rate for all pregnant women using this facility. It is also essential that a referral center such as the one in which the study was carried out should have a blood bank within its premises. Widespread education of women in the reproductive age in Ibadan, as well as their spouses on the importance of regular antenatal care and family planning is essential in order to reduce maternal deaths in this environment.

\section{REFERENCES}

Ahmed Y., Shehu C.E., Nwobodo E.I. and Ekole B.A. (2004). Reducing maternal mortality from ruptured uterus - the Sokoto intiative. African Journal of Medical Science 33(2): 135-138.

Begum, S., Nisa, A. and Begum, I. (2003). Analysis of maternal mortality in a tertiary care hospital to determine causes and preventable factors. J. Ayub.Med. Coll. Abboattabad. 15:2.

Chhabra S., Kaipa A. and Kanani A. (2005). Reduction in Maternal mortality due to sepsis. Journal of Obstetrics and Gyaecology 25(2): 140-142.

Daramola, A.O., Banjo, A.A. and Elesha, S.O. (2004). Maternal deaths in the Lagos University Teaching Hospital: a ten-year review (1989 - 98). Nigerian Postgraduate Medical Journal. 11(4): 274 - 278.

De Browere V. (1998). Strategies for reducing maternal mortality in developing countries: What can we learn from the history of the industrialized West? Tropical Medicine and International Health 3(10): 771-782.

Duley L. (1992). Maternal mortality associated with hypertensive disorders of pregnancy in Africa, Asia, Latin America and the Caribbeans. British Journal of Obstetric and Gynaecology 99:547-553.

Garenne, M., Mbaye, K., Bah, M.O. and Correa, P. (1997). Risk factors for maternal mortality: a case-control study in dakar hospitals (Senegal). African Journal of Reproductive Health 1(1): 14-24.

Grant J.P. (1990). State of the World's Children, New York Oxford University Press, 1990.

Harrison, K.A. (1997). Maternal mortality in Nigeria: the real issues. African Journal of Reproductive Health 1 (1): 7-13.

Howson C.P., Harrison P.F., Hana D. and Law M. 
(eds). (1996). In her lifetime - female morbidity and mortality in sub-Saharan Africa. National Academy Press, Washington DC, USA, 1996.

Jacob S., Bloebaum L., Shah G. and Varner M.W. (1998). Maternal Mortality in Utah, Obstetrics and Gynaecology 91: 187-191.

Matthews M. (2005). Improving Maternal and Child Survival in India. Indian Journal of Medical Research 121: 621-627.

Moodley J. and Moodley D. (2005). Management of Human Immuno-Deficiency Virus Infection in Pregnancy. Best Pract. Clin. Obstet. Gynaecol, 19(2): 169-183.

National Population Commission (2003). Nigeria Demographic and Health Survey (2003). IRD Macro International USA.

Oladapo, O.T., Lamina, M.A., and Fakoya, T.A. (2006). Maternal deaths in Sagamu in the new millennium: a facility-based retrospective analysis. Bio.Med Central Pregnancy and Childbirth 6:6

Onuh S.O. and Aisien A.O. (2004). Maternal and Fetal Outcome in Eclamptic Patients in Benin City, Nigeria. J. Obstet. Gynaecology 24(7): 765-768.

Rosenfield A. (1989). Maternal Mortality in Developing Countries. An ongoing but neglected tragedy. JAMA
262(3): 376-379.

Rush D. (2000). Nutrition and Maternal Mortality in the Developing World. American Jorunal of Clinical Nutrition 72(1): 22-240.

Shiffman J. (2000). Can poor countries surmount high maternal mortality? Studies in Family Planning, 31(4): 274-289.

World Health Organization (1992). International Classification of Diseases and health-Related Problems in the 10th Revision, Volume 2. World Health Organization, Geneva.

World Health Organization (1997). Coverage of Maternal Care: A Listing of Available Information, 4th edition, WHO, Geneva.edition, WHO, Geneva.

World Health Organization (1998). Abortion: A Tabulation of Available Information, 3rd edition. World Health Organization, Geneva.

World Health Organization (1999). Reduction of Maternal Mortality: A Joint WHO/UNFPA/UNICEF/World Bank Statement, WHO, Geneva.

World Health Organization (2004). Maternal Mortality in 2000: Estimates Developed by WHO, UNICEF and UNFPA. World Health Organization, Geneva. 